Eurasian Journal of Physics and Functional Materials

2021, 5(4), 188-197

\title{
Analysis of the beryllium stability under standard and critical operation in a fusion reactor
}

\author{
I.A. Sokolov ${ }^{* 1}$, M.K. Skakov ${ }^{2}$, A.Zh. Miniyazov ${ }^{1}$, \\ B.T. Aubakirov ${ }^{1}$, T.R. Tulenbergenov ${ }^{1}$, A.V. Gradoboev ${ }^{3}$ \\ ${ }^{1}$ Institute of Atomic Energy Branch RSE NNC RK, Kurchatov, Republic of Kazakhstan \\ ${ }^{2}$ National Nuclear Center of the Republic of Kazakhstan, Kurchatov, Republic of Kazakhstan \\ ${ }^{3}$ Tomsk Polytechnic University, Tomsk, Russia \\ E-mail: sokolov@nnc.kz
}

DOI: $10.32523 /$ ejpfm.2021050403

Received: 25.09.2021 - after revision

\begin{abstract}
The paper provides data on the peculiarity of change in the structure, structural phase changes and destructions in beryllium resulting from interaction with a near-wall plasma of fusion facilities. Beryllium resistance under conditions of ITER operation was evaluated, which considers factors leading to possible partial melting and erosion of panels of the ITER first wall. It presents the modelling of a heat s distribution in element ("finger") of the first wall at "normal" and "increased" heat flux of the ITER operation.
\end{abstract}

Keywords: ITER, beryllium, plasma, Tokamak, fusion, electron beam, heat load, hydrogen.

\section{Introduction}

As it is known, the ITER blanket modules are one of the most complex components of a fusion reactor since they are an inner part of the reactor, which is directly affected by plasma. They consist of a first wall panel (FWP) mechanically bounded with a defensive unit mounted to a vacuum vessel using flexible supports and keys. The main concern is that plasma-faced materials are destroyed in Tokamaks due to thermal and radiation effects. The frequent overloads lead to 
module fatigue, melting of a surface, and rupturing of cooling channels, which can finally lead to water leakage and replacement of components.

Figure 1 shows that there are two values of the heat load for FWP depending on how chamber sections are located on the plane [1]: "normal" heat flux with a load of $2 \mathrm{MW} / \mathrm{m}^{2}$ and "increased" heat flux with a load of $4.7 \mathrm{MW} / \mathrm{m}^{2}$. Typical FWP consists of a number of such called "fingers" presenting joint blocks of the ITER chamber facing and designed to withstand 15000 cycles under such loads.

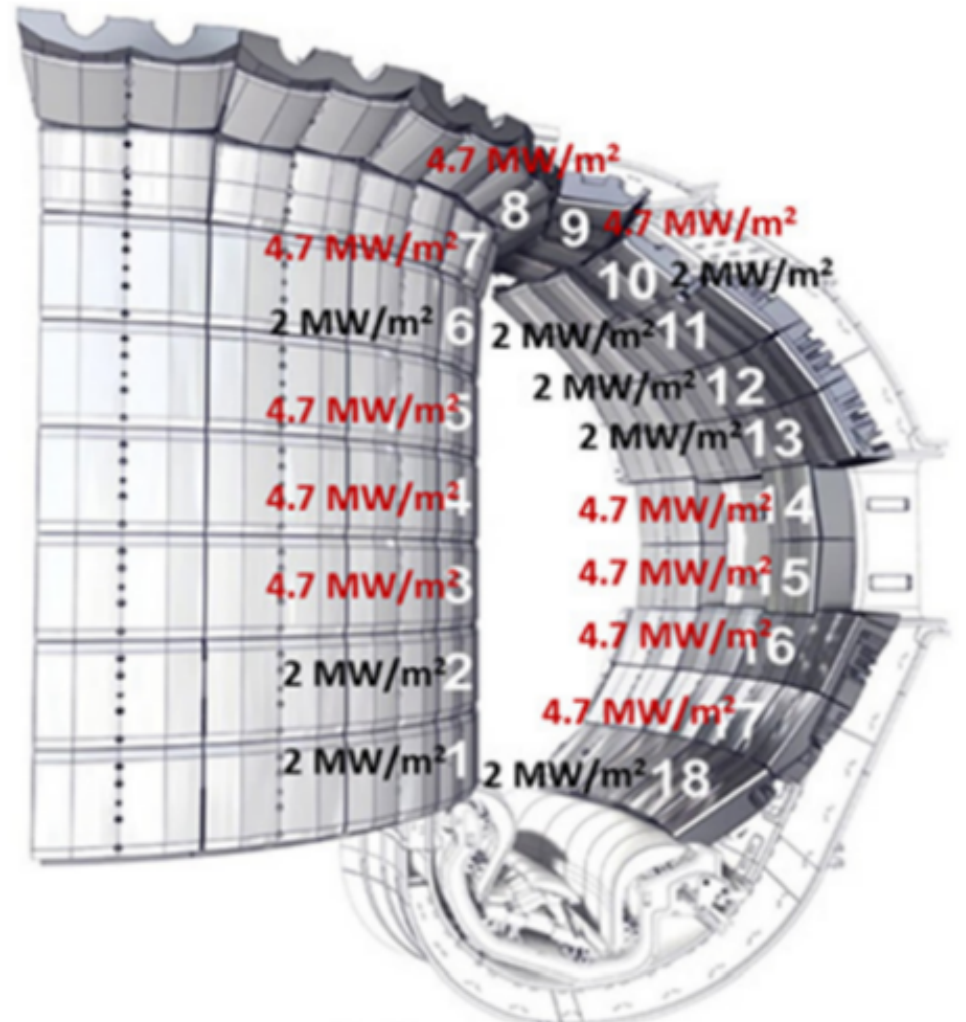

Figure 1. Poloidal cross-section of the ITER Tokamak with designed limitations of a heat flux [1]

During the ITER operating, beryllium facing of the FWP will be subjected to the cycle heat loads that will give raise to both constant and cycle fatigue loads of a medium level and various plasma instability (transitional processes) triggering high local voltages (VDE, ELM). All these physical phenomena can lead to a surface melting, cracking, evaporation and beryllium erosion [1].

\section{Evaluation of beryllium resistance under conditions of the ITER operation}

The most important requirement for Be as a facing material, is its resistance to a heat shock and fatigue, since cracking leads not only intensive Be erosion, but to a defect of a connection with copper heat removal structure.

The grades of beryllium, which are regarded as candidates for the first wall facing of a fusion reactor (FR) are: US grade S-65 VHP (Materion Brush Beryllium and Composites), Chinese grade CN-G01 (CNMC, Ningxia Orient Group Co. Ltd) and Russian grade TGP-56PS (Bochvar Institute of Inorganic Materials) [2]. 
They differ by chemical composition, powder preparation process, compression method, etc. In this work we took domestic grade of beryllium TGP-56 of Kazakhstani production [3]. A high heat capacity and good thermal conductivity of Be can be used for maintaining low temperatures of surfaces in the FWP during standard operation. However its low melting temperature high erosion trigger a number of problems when ITER designing in terms of operation with VDE and ELM phenomena.

Over the past few years, an interesting data has been obtained on interaction between beryllium with plasma, neutron flux and hydrogen isotops from available tokamaks, experimental reactors and simulation benches. This data had resulted in some success in understanding the processes associated with plasma interaction with material surface [4-9].

The phenomena associated with changes in the surface structure when plasma beams affect the first wall materials and divertor plates of the fusion facilities are of great importance [10-12]. The result plasma effect on the material is spattering and evaporation of the material, change in structure and phase state of the material, generation of new chemical compounds on the surface, etc. [13]. Thus, in our opinion, experiments to study processes occurring at plasma disruption, when a temperature and plasma density lead to the melting, evaporation and erosion of the reactor materials, are essential. In combustion of a fusion plasma, the plasma-faced components are subjected to a strong heat fluxes, plasma particles $(\mathrm{H}, \mathrm{D}, \mathrm{T})$, and $\mathrm{He}+$ ion bombardment with an energy of $3.5 \mathrm{MeV}[14,15]$.

The goal of this work is to evaluate endurance of beryllium coating as facing material of the ITER first wall in standard operation conditions and at plasma disruption of a fusion reactor.

In order to achieve the desired goal in this work, the following tasks have been solved:

1. Research to evaluate beryllium resistance has been substantiated based on the actual operating conditions in a fusion reactor.

2. Possible partial melting of the material and erosion of the ITER first wall panels at transient processes, plasma disruptions have been analyzed based on designed power of the heat flux, location of panels and cooling conditions during the ITER operating.

3. Data on temperature distribution in the first wall component has been obtained based on simulation of the heat flux effect in the ITER for future experimental work.

\section{Factors leading to possible partial melting and erosion of the ITER first wall panels}

In tokamaks, a large amount of plasma heat follows along power lines of the magnetic fields. The heat flux density parallel to the power lines can achieve 1 $\mathrm{GW} / \mathrm{m}^{2}$ in the ITER, which far exceeds technical capabilities of any stationary thermal protection. Physical response in the ITER is aimed at achieving a high rate of fusion synthesis, QDT=10, for durations in the range of 300-500 s [16]. In 
such discharges the heat power crossing a plasma boundary, corresponding to $\approx 100 \mathrm{MW}$, should be transferred to FWP.

These heat flux is reduced to $2-4.7 \mathrm{MW} / \mathrm{m}^{2}$ due to sliding incident angles of the magnetic field lines on the first wall. The angle of plasma sliding along the first wall panels is due to a strong toroidal component of the magnetic field. The sliding angles are from $1^{\circ}$ to $5^{\circ}$. However, at the joints between FWPs, plasma interaction is possible on the edges of the beryllium panels, they are shown in Figure 2, which take place as a consequence of diagnostics and technological ports in the FWP $[17,18]$. In these areas, exposure to plasma and heat flux is possible at angles from $15^{\circ}$ to $90^{\circ}$, which can lead to local heat load, possible partial melting of components and plasma contamination.

Shaping wall components reduces heat load on edges by deepening the edges and placing those edges in areas shaded by adjacent components. Locally, full shading of the beryllium tile edges would require local shaping of each panel, which is hardly realistic for industrial scale components. A solution to the situation was achieved based on developed design that excludes accept of the main heat load on components and tile edges [19], but some heat flux will enter the shaded area as a result of the constructive assembly tolerance of $5 \mathrm{~mm}$ between the panels.

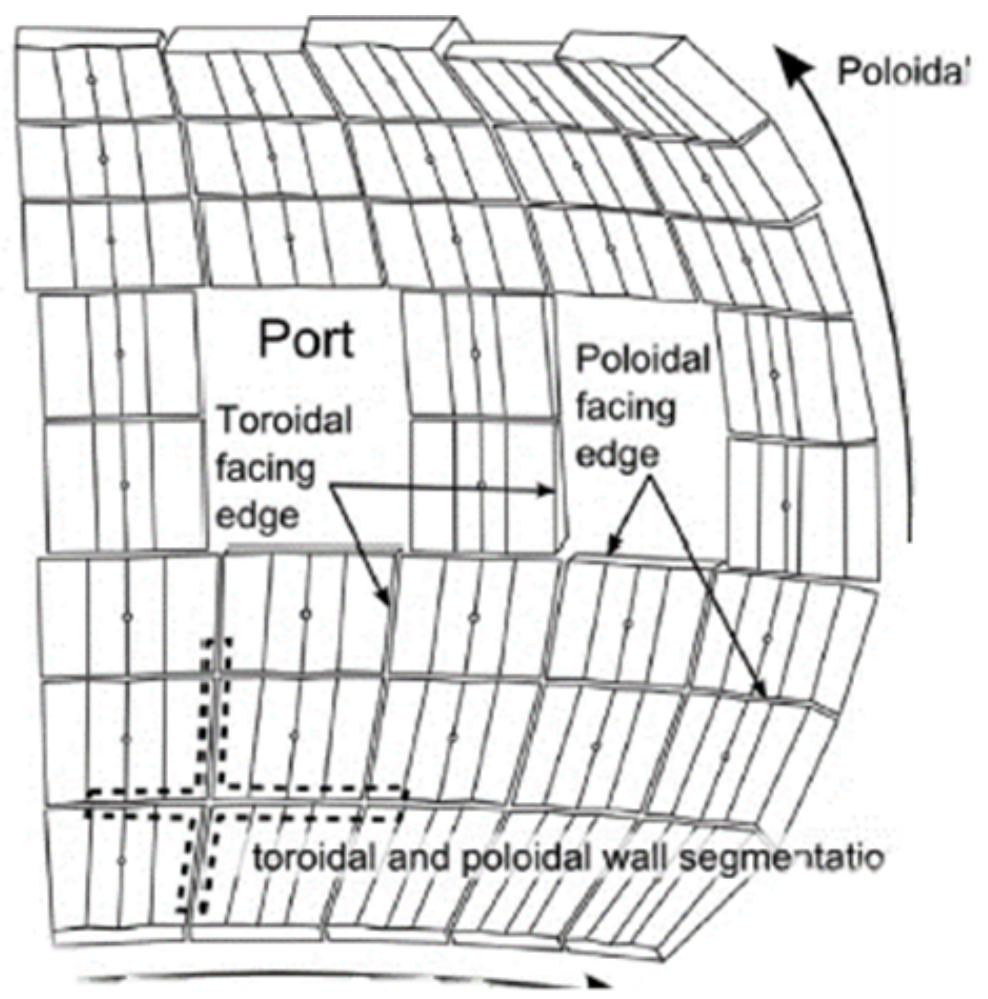

Figure 2. Schematic illustration of the external first wall of the ITER in a global scale with component gaps and port orifices [19].

Increased wear of beryllium leads to a reduction in its service life, and will also negatively affect the connection between the components of the first wall blanket. To prevent these risks, a maximum permissible temperature of $800^{\circ} \mathrm{C}$ is adopted at the tile edges. The components of the first water-cooled wall are connected together by soldering or diffusion. Apparently, the problem of edge 
heat load becomes even more critical for these compounds.

\section{Simulation of the heat load distribution in the ITER first wall component}

The first wall structure is based on a strong supporting steel beam, oriented in the poloidal direction, as Figure 3 shows [20]. The beam supports elongated plasma-facing blocks consisting of $0.5-0.9 \mathrm{~m}$ long "fingers" attached to the beam in a toroidal direction with a protrusion to fully enclose the protection block. The "fingers" consist of a bimetallic support structure made of copper-chromiumzirconium (CuCrZr) alloy 15-25 mm thick, bonded to 40-50 mm steel. Beryllium tiles up to $10 \mathrm{~mm}$ thick are bonded to a $\mathrm{CuCrZr}$ layer [20].

Distilled water is used as a coolant. The water temperature at the cooling path inlet is $70^{\circ} \mathrm{C}$. The coolant movement in the radiation area is $5 \mathrm{~m} / \mathrm{s}$ or higher, and is about $2 \mathrm{~m} / \mathrm{s}$ in the area of the hypervapotron modules, which in turn provides a reserve for obtaining a critical heat flux at the end of the structure tube at an inlet temperature of $70^{\circ} \mathrm{C}$ and pressure of $4 \mathrm{MPa}$. The relevant exact value for the pressure drop is $0.38 \mathrm{MPa}$, but specified value for the first wall calculations is $0.4 \mathrm{MPa}$.

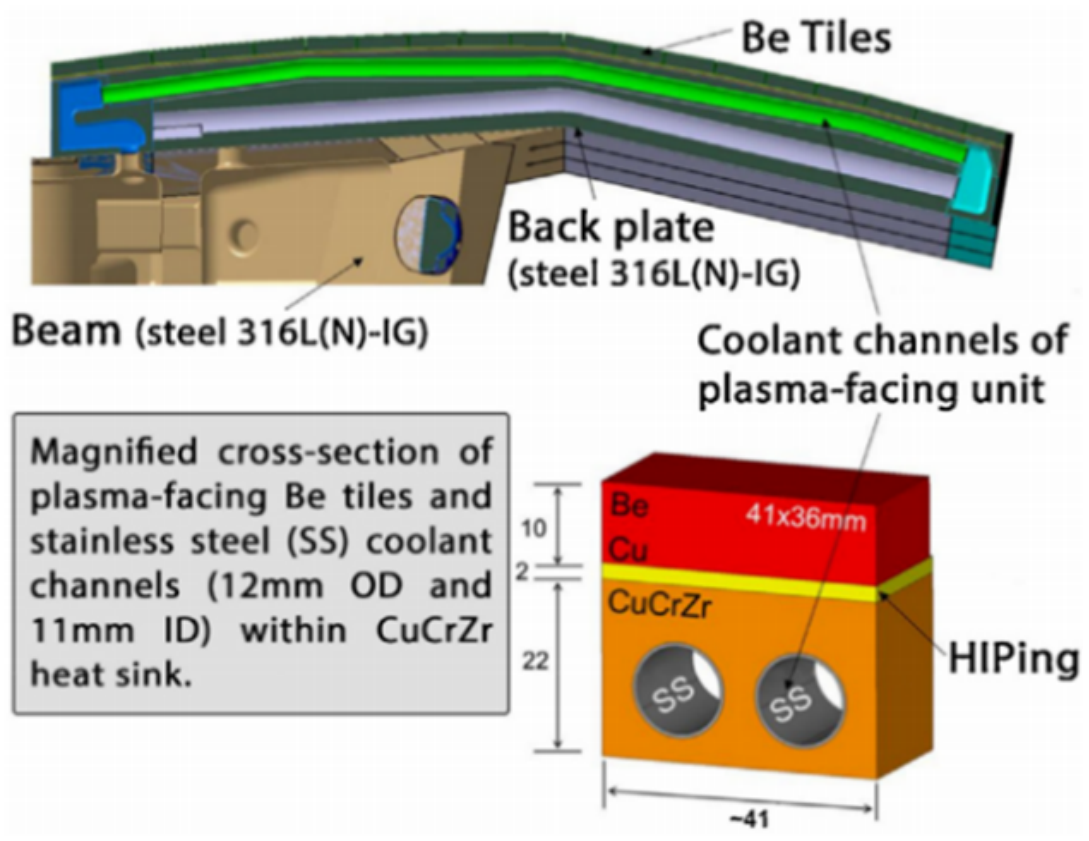

Figure 3. Structure of the first wall panel [20]

The obtained data on the temperature distribution in the ITER first wall component were determined using the Autodesk CFD software package [21].

In order to achieve the goal set in the project of MES RK grand funding AP08856026, a computational model was constructed and the effect of heat loads of $2 \mathrm{MW} / \mathrm{m}^{2}, 4.7 \mathrm{MW} / \mathrm{m}^{2}$ and $7.8 \mathrm{MW} / \mathrm{m}^{2}$ was simulated, as shown in Figure 4. The last calculated capacity was determined for the critical condition of beryllium temperature $1200^{\circ} \mathrm{C}$. 

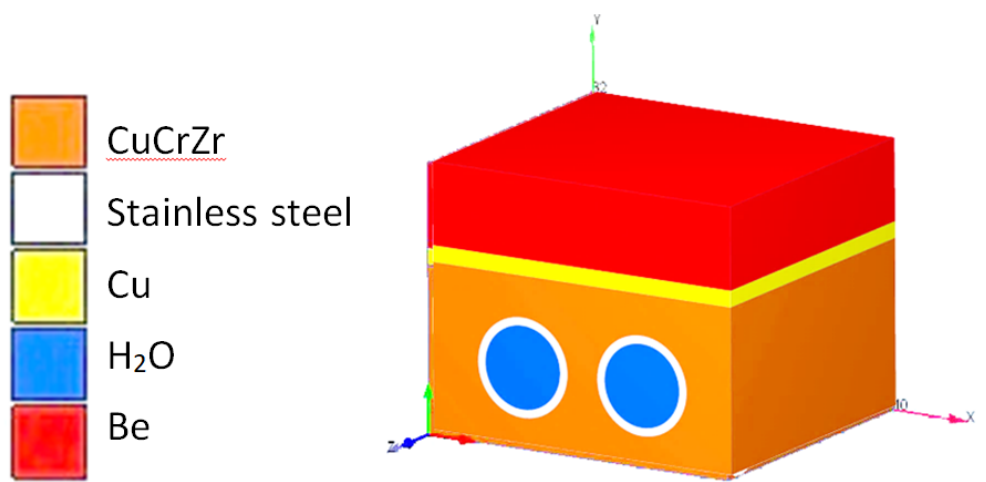

Figure 4. Model of the ITER first wall panel in the computational program.

It can be seen that temperature distribution in the model depends on the heat flux density, thermal conductivity of materials, as well as convective heat exchange with water.

The heat flux of the corresponding density is set on the upper surface of the model.

During calculation, convective heat transfer is set using the heat transfer rate to the cooling path surface, the water temperature value is taken equal to $70^{\circ} \mathrm{C}$.

The heat transfer rate from the cooling path to the water is determined by the formula [22]

$$
\begin{aligned}
& \alpha_{1}=\frac{N u_{1} \cdot \lambda}{d}=\frac{193.8 \cdot 0.662}{0.011}=11.7 \cdot 10^{3} \mathrm{~W} /\left(\mathrm{m}^{2} \times \mathrm{S}\right), \\
& \alpha_{2}=\frac{N u_{2} \cdot \lambda}{d}=\frac{402.8 \cdot 0.662}{0.011}=24.2 \cdot 10^{3} \mathrm{~W} /\left(\mathrm{m}^{2} \times \mathrm{S}\right),
\end{aligned}
$$

where $N u$ - Nusselt number for water, calculation formula is given below; $\lambda-$ heat transfer rate for water at a temperature of $70^{\circ} \mathrm{C} . \lambda_{B}=0.662 \mathrm{~W} /\left(\mathrm{m} \times{ }^{\circ} \mathrm{C}\right) ; d-$ cooling path diameter, $d=0.011 \mathrm{~m} \mathrm{[20].}$

To determine the Nusselt number, it is required to calculate the Reynolds number

$$
\begin{aligned}
& \operatorname{Re}_{1}=\frac{\rho \cdot d \cdot v_{1}}{\mu}=\frac{10^{3} \cdot 0.011 \cdot 2}{404 \cdot 10^{-6}}=5.45 \cdot 10^{4}, \\
& \operatorname{Re}_{2}=\frac{\rho \cdot d \cdot v_{2}}{\mu}=\frac{10^{3} \cdot 0.011 \cdot 5}{404 \cdot 10^{-6}}=1.36 \cdot 10^{5},
\end{aligned}
$$

where $v$-water speed, $v_{1}=2 \mathrm{~m} / \mathrm{s}, v_{2}=4 \mathrm{~m} / \mathrm{s} ; \mu$-dynamic viscosity factor of water at a temperature of $70^{\circ} \mathrm{C}, \mu=404 \times 10^{-6} \mathrm{~Pa} \cdot \mathrm{s}$.

$S$ - cross-sectional square of the cooling path, $\mathrm{m}^{2}$. The cross-sectional square of the cooling path is

$$
S=0.25 \cdot \pi \cdot d^{2}=0.25 \cdot 3.14 \cdot 0.011^{2}=9.5 \cdot 10^{-5} \mathrm{~m}^{2},
$$

At the Reynolds number values above $10^{4}$, a developed turbulent flow regime is established. For this flow regime, the Reynolds number is calculated by the formula [22] 


$$
\begin{aligned}
& N u_{1}=0.021 \cdot \operatorname{Re}_{1}^{0.8} \operatorname{Pr}^{0.43}=193.8, \\
& N u_{2}=0.021 \cdot \operatorname{Re}_{2}^{0.8} \operatorname{Pr}^{0.43}=402.8,
\end{aligned}
$$

where $\mathrm{Pr}$ - Prandtl number for water at $70^{\circ} \mathrm{C}, \mathrm{Pr}=2.58$.

Figures $5(\mathrm{a}, \mathrm{b}, \mathrm{c})$ show the temperature field of the computational model at constant cooling and heat flux density of $2 \mathrm{MW} / \mathrm{m}^{2}, 4.7 \mathrm{MW} / \mathrm{m}^{2}$ and 7.8 $\mathrm{MW} / \mathrm{m}^{2}$, respectively. Temperatures are given in Celsius degrees.
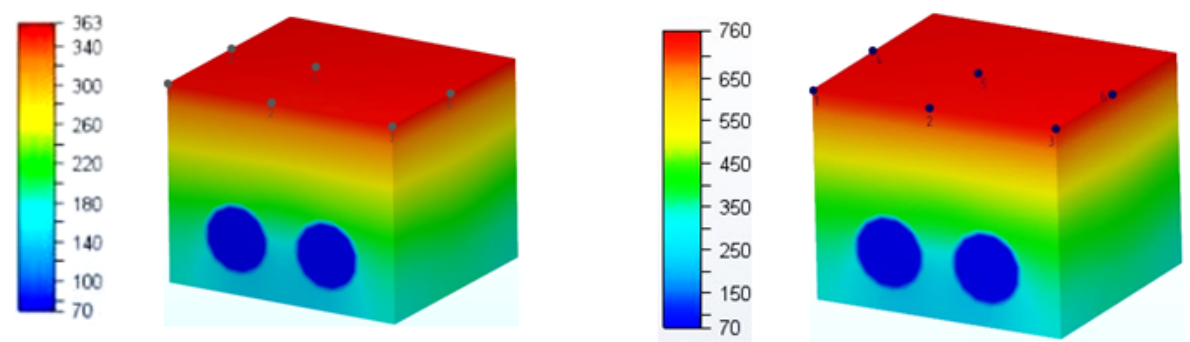

a) heat flux of $2 \mathrm{MW} / \mathrm{m}^{2}$

b) heat flux of $4.7 \mathrm{MW} / \mathrm{m}^{2}$
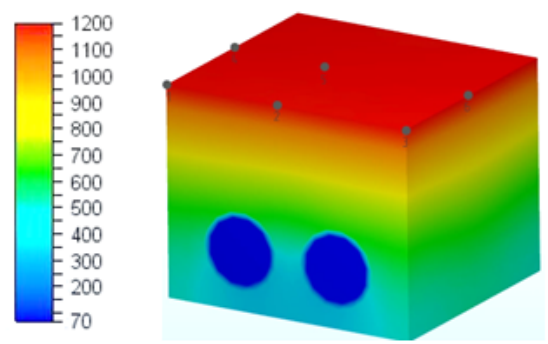

c) heat flux of $7.8 \mathrm{MW} / \mathrm{m}^{2}$

Figure 5. Computational temperature field of model.

Table 1 shows the temperature values at the control points shown in Figure 6 at powers of $2 \mathrm{MW} / \mathrm{m}^{2}, 4.7 \mathrm{MW} / \mathrm{m}^{2}$ and $7.8 \mathrm{MW} / \mathrm{m}^{2}$.

Table 1.

Calculation temperature in the control points of the first wall.

\begin{tabular}{l|l|l|l}
\hline \multirow{2}{*}{ Control point } & \multicolumn{3}{|c}{ Temperature, ${ }^{\circ} \mathrm{C}$} \\
\cline { 2 - 4 } & $\mathrm{q}=2 \mathrm{MW} / \mathrm{m}^{2}$ & $\mathrm{q}=4.7 \mathrm{MW} / \mathrm{m}^{2}$ & $\mathrm{q}=7.8 \mathrm{MW} / \mathrm{m}^{2}$ \\
\hline 1 & 357 & 737 & 1167 \\
\hline 2 & 330 & 681 & 1077 \\
\hline 3 & 357 & 737 & 1167 \\
\hline 4 & 310 & 641 & 1014 \\
\hline 5 & 279 & 577 & 912 \\
\hline 6 & 310 & 641 & 1014 \\
\hline
\end{tabular}

Table 2 shows the results of calculating the temperature in the materials of the "finger" of the first wall under the conditions of the heat flux values of 2 $\mathrm{MW} / \mathrm{m}^{2}, 4.7 \mathrm{MW} / \mathrm{m}^{2}$ and $7.8 \mathrm{MW} / \mathrm{m}^{2}$. 


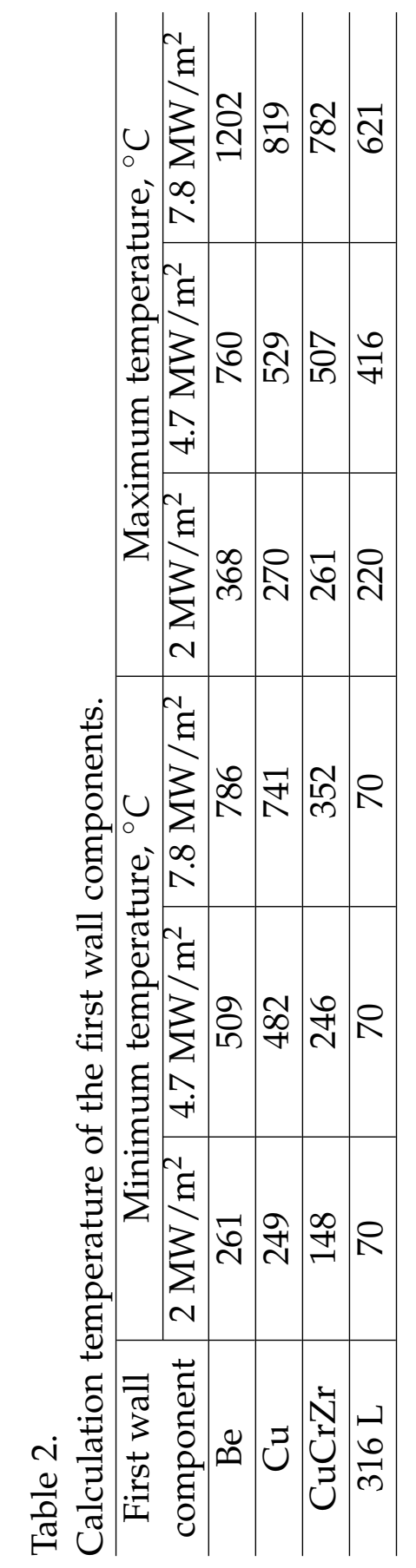




\section{Conclusion}

Depending on the of the ITER chamber location on the inner plane, for the first wall there is a "normal" heat flux with a load of $2 \mathrm{MW} / \mathrm{m}^{2}$ and an "increased" heat flux with a load of $4.7 \mathrm{MW} / \mathrm{m}^{2}$. During the ITER operation, beryllium lining of the first wall will be subjected to cyclic thermal loads, which will cause both constant and cyclic fatigue loads, which can trigger surface melting, cracking, evaporation and erosion of beryllium.

The research results of testing various beryllium grades may conclude that the beryllium of Kazakhstan production of TGP-56 grade can be used as a first wall coating of fusion facilities.

Modeling of the temperature distribution in the "fingers" of the blanket structure of the ITER first wall under standard and critical thermal load conditions has been carried out. It was found that with a "normal" heat flow of $2 \mathrm{MW} / \mathrm{m}^{2}$, the maximum temperature of beryllium will be $\approx 360^{\circ} \mathrm{C}$, with an "increased" heat flow of $4.7 \mathrm{MW} / \mathrm{m}^{2}$ - about $733^{\circ} \mathrm{C}$. These data will be used for experimental modeling of the heat load effect on TGP-56 beryllium in future experimental studies.

\section{Acknowledgments}

This research is funded by the Science Committee of the Ministry of Education and Science of the Republic of Kazakhstan (Grant No. AP08856026).

\section{References}

[1] A.R. Raffray et al., Nuclear Fusion 54 (3) (2014). [CrossRef]

[2] V. Barabash et al., Physica Scripta 145 (2011) 014007.[CrossRef]

[3] Available online: http://www.ulba.kz/ru/production2_06.htm (accessed on 21 August 2021).

[4] A. Kallenbach et al., Plasma Physics and Controlled Fusion 47 (2005)

B207-B222. [CrossRef]

[5] R. Mitteau et al., Fusion Engineering and Design 88 (2013) 568-570. [CrossRef]

[6] A. Volodin et al., Fusion Engineering and Design 98-99 (2015) 1411-1414.

[CrossRef]

[7] G. Pintsuk et al., Nuclear Materials and Energy 9 (2016) 41-45. [CrossRef]

[8] B. Spilker et al., Nuclear Materials and Energy 18 (2019) 291-296. [CrossRef]

[9] I. Kenzhina et al., Journal of Nuclear Science and Technology 58(1) (2020) 1-8. [CrossRef]

[10] Available online: https://www.iter.org/ (accessed on 21 August 2021).

[11] ITER Technical Basis, IITER EDA DOCUMENTATION SERIES No. 24

(International Atomic Energy Agency, Vienna, 2001). [Web-Link]

[12] H. Bolt et al., Journal of Nuclear Materials 329-333(1) (2004) 66-73. [CrossRef]

[13] M. Merola et al., Fusion Engineering and Design 96-97 (2015) 34-41.

[CrossRef] 
[14] F. Kong et al., Nuclear Instruments and Methods in Physics Research 406 (2017) 643-647. [CrossRef]

[15] R.K. Janev et al., Atomic and plasma-material interaction data for fusion (International Atomic Energy Agency, Vienna, 1994) 103-117. [Web-Link] [16] ITER Physics Expert Group on Confinement and Transport et al., Nuclear Fusion 39(12) (1999) 2175-2249. [CrossRef]

[17] R. Mitteau et al., Nuclear Materials and Energy 12 (2017) 1067-1070. [CrossRef]

[18] JET Team, Nuclear Fusion 32 (1992) 187-203. [CrossRef]

[19] Y. Corre et al., Journal of Nuclear Materials 463 (2015) 832-836. [CrossRef] [20] T. Cicero et al., Fusion Engineering Design 98-99 (2015) 1256-1262. [CrossRef] [21] Available online: www.autodesk.com/campaigns/cfd2020 (accessed on 21 August 2021).

[22] M.A. Mikheev, I.M. Mikheeva, Fundamentals of heat transfer (Energia, Moscow, 1977) 342 p. [Web-Link] (In Russian) 